\title{
Non-organized boycott: alliance advantage and free riding incentives in uneven wars of attrition
}

\section{Yi Zheng ${ }^{1}$}

Received: 1 April 2019 / Revised: 7 August 2019 / Accepted: 9 August 2019 / Published online: 26 August 2019 (C) The Author(s) 2019

\begin{abstract}
We study non-organized boycott activities. We develop a boycott model where multiple consumers on the demand side fight against a misbehaved monopolist on the supply side. The goal of the boycott is to force the firm that lacks corporate social responsibility to change its behavior, for example, abandon polluting production technology towards environmentally friendly actions. We analyze consumers' and firm's incentives and equilibrium strategies. Our paper describes the difficulty of winning a non-organized boycott in reality. We find that consumers' free riding incentives limit the real boycott power even when the benefits to free ride is small. The larger the market the firm serves, the more likely an individual consumer would stop boycotting (who acts as a strict environmentalist), which leaves fewer boycotters remaining in the costly conflict (who act as loyal supporters of the product). On the other hand, we show that the market size does not significantly affect the firm's strategies. For a big firm, the consumer boycott will surely be effective, that is, lead to non-zero boycotter participation, but hardly successful, that is, not lead to the firm's cessation of misbehavior.
\end{abstract}

Keywords War of attrition · Free riding incentives · Mixed strategy nash equilibrium $\cdot$ Non-cooperative game $\cdot$ Consumer boycott

JEL Classification C7 · D42 · D7

\section{Introduction}

A firm lacking the awareness of corporate social responsibility and deviating from a general accepted level of social norm may be boycotted by consumers (Fehr and Fischbacher 2004). Boycott can be launched and influenced by non-governmental

Yi Zheng

yi.zheng@helsinki.fi

1 University of Helsinki, Arkadiankatu 7, 00014 Helsinki, Finland 
organizations (NGOs) or more commonly, non-organized voluntary consumer activism. ${ }^{1}$

Sometimes the boycotting group wins: the targeted firms are 'forced' to behave in a way that benefits the interest of boycotters. However, surprisingly, most of the time boycotts fail. This is so even when the number of the participating boycotters is initially large. There are some clear difficulties for the success of boycotts. First, a pure profit-driven firm may act without much concern of social norms. Being 'patient' enough, a firm can simply ignore boycotters' behavior and the potential damage of corporate image and reputation as long as its financial loss remains at an acceptable level. Second, free riding problem exists. Since the success of boycott generally does not require the contribution of all consumers in the market, each self-interested individual thus, more or less, has incentives to free ride on the collective actions of other boycotters. Third, the non-consistency of boycotters' behavior limits the financial and reputational damage to the misbehaved firm. In most of the cases, only very few consumers stop purchasing from the non-ethical firm 'permanently' (before boycott success is achieved). Many boycotters may not continuously fight against the firm for a long period of time which limits the real boycotting power. Consumers may act like 'forgiving' the unethical firm which is in fact driven by selfishness and free ride incentives. Fourth, there are the non-commitment and non-binding features. Boycotting as a consumer's independent choice is not under any binding obligations. It implies the great difficulty, in fact almost impossibility, of boycotting coordination. Fifth, threatening to boycott has limited boycott power. Even if the boycotting is organized by some NGOs, it is more of a 'threat to boycott' rather than 'physical boycotting activity'. The firm may view consumers' threats as cheap talk. Last but not least, the ongoing boycott may turn out to be harmless. The consistency of few consumers' boycotting behavior does not necessarily achieve any good outcomes. An unethical firm can ignore this group-if indeed there is sufficient boycotting power that leads to a huge profit loss, the firm would have already changed its behavior in the first place. The firm only becomes more 'patient' and 'persistent' to fight against the ongoing boycotters over time with the hope of obtaining their potential 'forgiveness'.

In this paper, we develop a non-cooperative game between a profit driven firm that lacks of social responsibility and a number of potential boycotters who have environmental concerns. We try to address the following questions: on the demand side, which incentive dominates the consumer's behavior, moral concern (to boycott

\footnotetext{
1 There are many underlying causes of boycott activity, for example, inappropriate promotion of infant formula in developing countries (Nestlé), war (limit trade with Russia due to Ukraine), political reasons (US boycott of French wine 2003), protecting a river delta (Shell Oil), Soviet violations of human rights and invasion of Afghanistan (1980 Summer Olympics), abuse of monopoly power (Microsoft), unfair wages (Delano grape), production of genetically modified organisms (Monsanto), child labor (Nike and Lush's supply chain in Jharkand, India), animal rights (KFC), product featured with criticism slogan (Abercrombie \& Fitch in USA), destroying agricultural farms, greenhouses, ancient olive groves (Caterpillar's D-9 bulldozers in Palestine), conserving energy and reducing carbon emissions (the Close the Door campaign in UK), continuing rise of food prices (Cottage cheese in Israel), climate change denial and lack of investment in renewable energy (Esso/ExxonMobil), deepwater horizon oil spill (BP) and more recently, location of factory (Oreo) and independence (SodaStream), just list a few.
} 
and do the right thing) or selfishness (not to boycott and care about the subjective utility maximizing)? Why some consumers act like strict environmentalists (are willing to boycott with fighting costs for a long time) while others act like loyal supporters of the product (never participate in boycotts or boycott for a short period)? And on the supply side, whether the size of firm, i.e., the number of potential boycotters that the firm serves, matters, and if so, to what extent?

Our model extends Maynard Smith (1974)'s classic two-contestant game of war of attrition. We introduce free riding incentives and alliance advantages to players on the demand side. Consumers form a weak alliance to fight against a misbehaved monopolist. Taking side to the boycotters/alliance is cost-free but potentially beneficial. No commitment to fully cooperate is required. Meanwhile, a prize may be awarded to a free riding consumer even without providing a personal contribution. We allow a prize to a successful free rider if the game eventually ends with his ally's success. Each consumer wishes to obtain a prize with less effort.

We start from a two-against-one game. By comparing the mixed strategy equilibrium in our model to that of a classic two-contestant game, we examine the effect of the third player's intervention. We discuss how consumers behave in the presence of potential support from the alliance and how the firm deals with it. We then let the number of players on the demand side increase to infinitely large. We find a unique mixed strategy equilibrium in the $n$-against-one game. We derive optimal strategies of both sides at the limit.

Our results explain the difficulty of winning a non-organized boycott in reality. On the demand side, we find that the consumers' free riding incentives dominate their behaviors and therefore limit the real boycott power. The larger the market the firm serves, the more likely an individual consumer would surrender, which leaves fewer boycotters remaining in the costly conflict. We therefore explain the reason why some consumers act like loyal supporters of the product while others act like strict environmentalists. On the supply side, we show the market size does not significantly affect firm's strategies. A polluting firm would change its misbehavior with slightly higher probabilities in a large economy. For a big monopolist that serves infinitely many consumers, boycott will surely be effective, that is, non-zero participation, but hardly successful, that is, lead to the firm's cessation of misbehavior. ${ }^{2}$

Wars of attrition have been studied both theoretically and empirically by many economists and social scientists after (Maynard Smith 1974). However, only limited attention has been paid on the influence of a third contestant's contribution in a war of attrition framework taking account of alliance advantage and incentive to free ride. The closest studies to ours are Haigh and Cannings (1989), Bulow and Klemperer (1999) and Helgesson and Wennberg (2015) which discuss n-player competing for one or several prizes. Powell (2017) discusses the third party effects on a twoplayer game by allowing a third party to take sides and provide endogenous intervention to one of the two actors. He studies the case where a third party chooses a time to support one side after a conflict starts. Therefore at the time of joining the

\footnotetext{
${ }^{2}$ In Craig Smith (1990) paper, a boycott is 'effective' if there is non-zero participation and 'successful' if it leads to the cessation of the egregious act.
} 
game, the third party already forms a belief on the existing players' ability/strength ordering, the potential winning party and the expected length of the conflict. In this paper, we analyze a game within a game where the boycotters play a prisoners' dilemma against each other and meanwhile they form a weak alliance and play a war of attrition against the polluting firm.

Our research may also be linked with the literature on evolutionary games (see, e.g. Maynard Smith and Price 1973; Laruelle et al. 2018). Several papers studied boycotts, cooperation, punishment and environmental compliance (da Silva Rocha and Salomão 2019) or more general punishment and cooperation games (da Silva Rocha et al. 2015; da Silva Rocha 2017) using an evolutionary game setting. In these papers, rational behavior is partially relaxed and the dynamic nature of the evolutionary game is analyzed. In our paper, we employ a repeat game and assume players to be fully rational. Our model can be potentially extended to a two-population game where consumers' types and preferences change based on the interaction with other boycotters.

Several articles study consumer boycott in different settings. Friedman (1991) and Delacote (2008) provide conceptual discussion on boycott actions. Tyran and Engelmann (2005) provide an experiment on boycott in reaction to a sudden cost increase in retail markets. They find that the cost increases the incidence of boycotts. Boycotts reduce market efficiency. Innes (2006) develops a model where two nonidentical duopolists face a threat to boycott from an environmental organization. He finds that at equilibrium a small persistent boycott would fight against the small firm and a large transitory boycott would fight against the large firm. It implies larger firms are easier to be defeated. Baron (2001) employs a game between an influential activist and a monopolist that has concerns for profit maximization, altruism and activist's powerful threats. From a psychological perspective, John and Klein (2003) explain consumers' boycotting incentives and willingness to sacrifice. Heijnen and van der Made (2012) find that in a market under asymmetric information where consumers can signal high moral values, consumers always boycott with positive probability despite free-riding incentives and eventually results in a firm's behavior alternation. In a war of attrition framework, Peck (2017) analyzes a game between a monopolist that produces two-period durable goods and consumers that demand a lower price. He derives both non-boycott equilibrium and boycott equilibria where boycott occurs with positive probability. Egorov and Harstad (2017) develop a boycott game between a public regulator, a misbehaved firm and activists. They find that in a two-player game without the regulator, 'private politics' is beneficial for activists but harmful for firms. Meanwhile, in a three-player game, 'private politics' is harmful for activists but beneficial for firms. Our paper contributes to this literature by demonstrating that even if when the benefit of free riding is very small, it is sufficient enough to undermine the boycott success probability. We also discuss how market size affects a firm's decision making.

The rest of the article is organized as follows. In Sect. 2 we discuss the basic settings and underlying assumptions in a two-against-one game. The equilibrium results are in Sect. 3. In Sect. 4 we consider a general case where one firm fights against a side of many competitors. When the size increases to infinitely large, the equilibrium is derived at the limit. Section 5 concludes the paper. 
Table 1 A summary of flow payoffs

State-2: one target VS a weak alliance of two competitors

\begin{tabular}{lll}
\hline & Active fighters & \\
\cline { 2 - 3 } & Firm $(i t)$ & Each consumer $($ she or $h e)$ \\
\hline Cost of fighting & $-m$ per active consumer & $-c$ \\
Winning prize & $v$ & $w$ \\
Probability to quit & $q_{(2)}$ & $p_{(2)}$ \\
\hline
\end{tabular}

State-1: one target VS one remaining small competitor

\begin{tabular}{llll}
\hline & \multicolumn{2}{l}{ Active fighters } & Early quitter/free rider $(-i)$ \\
\cline { 2 - 4 } & Firm $(i t)$ & Remainer $(i)$ & \\
\hline Cost of fighting & $-m$ & $-c$ & 0 \\
Winning prize & $v$ & $w$ & $\epsilon$ \\
Probability to quit & $q_{(1)}$ & $p_{(1)}$ & 1 \\
\hline
\end{tabular}

$v>2 m>0, w>c>0, w>\epsilon>0$ eliminate 'instant surrender' equilibrium where either side or both sides do not bother to fight in the first place. State- $n$ represents the state of the game where $n$ demanders remain in the game actively

\section{Model}

Consider three players in a two-sided game of war of attrition competing for the winning prize under complete information: two consumers P1 (he) and P2 (she) on the demand side and one monopolist P3 (it) on the supply side. Consumers form a weak alliance where individual rewards and losses are determined by their joint actions. Consumers are identical. They are assumed, unless stated otherwise, to have the same incentives and play symmetric strategies. Time is discrete. In each period, players move simultaneously. The action set is binary: $a_{i} \in\{F, S\}, i \in\{1,2,3\}$ where $F$ and $S$ represent fight and surrender, respectively. Players have the same prior. P3's action $F$ is driven by lack of corporate social responsibility and therefore is viewed as amoral. The complementary action $S$ matches the generally accepted social norm and therefore is viewed as moral.

On the demand side, on one hand, driven by moral concern, consumers attempt to defeat the firm and force it change its behavior. On the other hand, selfish motivation gives rise to a prisoners' dilemma. Each consumer wishes the other to contribute more, that is, to allow him/herself to free ride on the alliance benefit. On the supply side, the firm chooses the best response to the joint action of the consumers. It wins the conflict only if every consumer is defeated. ${ }^{3}$

\footnotetext{
3 One may argue that in reality the monopoly supplier's decision may depend on the preferences and actions of the majority consumers. Thus, it would win (or lose) the game if, for example, half of the consumers surrender (or fight persistently). However, the selection of the winning cutoff point would not change the main results in this paper.
} 
The flow payoffs to the players are summarized in Table 1. In each period of a two-against-one game, active fighters pay a cost: $-c$ to each consumer and $-m$ per consumer to the firm. Only one side can win the game and no tie is allowed. The winning prize is $w$ to each consumer and $v$ to the firm. In the case when all three players surrender at the same time, each consumer benefits from the firm's concession and gets a second winning prize $\epsilon .{ }^{4}$ Once one and only one consumer surrenders, suppose it is P2, she becomes an early quitter and is not allowed to return to the conflict. The game becomes a standard one-against-one war of attrition where the remainer $\mathrm{P} 1$ has to fight alone against the firm. There is no more fighting cost to P2 after her surrender. Moreover, we allow her to get a prize as alliance benefit. If the game eventually ends with her ally's success, she gets the second prize $\epsilon$. If instead the firm is the final winner, the early quitter, along with the remaining consumer, gets zero. The common discount factor is $\delta \in(0,1)$.

The game of war of attrition is as illustrated in Table 2 . The game is played only once. It stops immediately if either side or both sides surrender at the same time. Otherwise, the game continues in State-2 if everyone remains, as Table 2a shows, or in State-1 if one of the consumers surrenders, as Table $2 b$ shows.

\section{Symmetric equilibrium}

We solve the game backwards. We start from State-1 where only one consumer remains in the game and fights against the firm alone. For a mixed strategy equilibrium to be possible, the indifference conditions to both active players, the remainer and the firm, should be satisfied. To the firm P3, in any time $t$, the utility of fighting for one more period $U_{3}(F)$ equals to that of surrendering immediately $U_{3}(S)$.

$$
\begin{aligned}
& U_{3}(F)=U_{3}(S) \\
& \quad \Rightarrow\left[-m+\beta_{1} \delta\right]\left[1-p_{(1)}\right]+v p_{(1)}=0
\end{aligned}
$$

where the continuation value $\beta_{1}=0$ at equilibrium. Solving the equation, we get

$$
p_{(1)}^{*}=\frac{m}{m+v}
$$

Suppose P2 is the early quitter. The remainer P1 is indifferent between staying in the conflict for one more period or quitting now.

$$
\begin{aligned}
& U_{1}(F)=U_{1}(S) \\
& \quad \Rightarrow\left[-c+\alpha_{1} \delta\right]\left[1-q_{(1)}\right]+w q_{(1)}=\epsilon q_{(1)}
\end{aligned}
$$

\footnotetext{
${ }^{4}$ The logic of the second winning prize comes from the unevenness of the game. Only consumers benefit from the supplier's concession in this case but not vice versa. Consider consumers stop boycotting and a polluting firm switches to a clean technology at the same time. Consumers get the utility from public good (the clean environment) but not from their moral values (concern for social responsibility and joy from defeating the firm).
} 
Table 2 A game of war of attrition among three players

(a) State-2: a 'two-against-one' game

P3

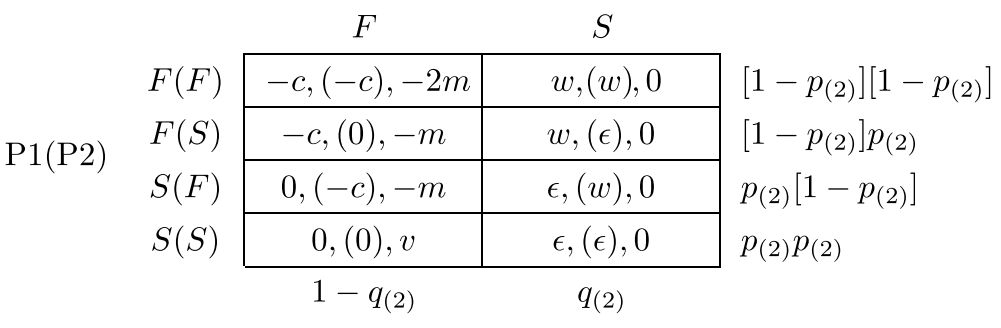

(b) State-1: a 'one-against-one' game

Opponent P3

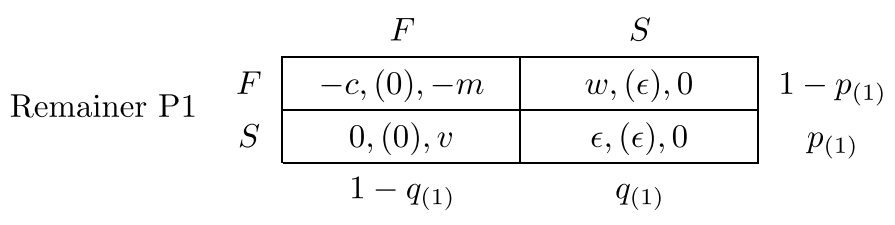

The actions and payoffs of the other player (P2) in parentheses in (a). The payoffs to the early quitter in parentheses in (b). The stopping probabilities to $\mathrm{P} 1, \mathrm{P} 2$ and $\mathrm{P} 3$ are $p(n), h(n)$ and $q(n)$, respectively, where $n \in\{1,2\}$ represents the number of the remaining players on the demand side. P1 and $\mathrm{P} 2$ are assumed to play the same strategy unless stated otherwise. The mixed strategy equilibrium is $\left(p_{(2)}^{*}, p_{(2)}^{*}, q_{(2)}^{*}\right)$ in State-2 if $\mathrm{P} 1$ and $\mathrm{P} 2$ play symmetric strategies. The mixed strategy equilibrium is $\left(p_{(1)}^{*}, 1, q_{(1)}^{*}\right)$ in State-1 if P2 surrenders and the game continues as a 'one-against-one' war of attrition. At equilibrium, the continuation values to each active fighting consumer are $\alpha_{1}, \alpha_{2}, \alpha_{3}$. In State-1, the continuation values are $\alpha_{1}$ to the remaining consumer and $\alpha_{2}$ to the early quitter. At equilibrium, the continuation values to $\mathrm{P} 3$ are always zero therefore not highlighted separately

where the continuation value

$$
\alpha_{1}=\left[1-p_{(1)}\right] U_{1}(F)+p_{(1)} U_{1}(S)=\epsilon q_{(1)}>0
$$

at equilibrium. Since the quitting probability $q_{(1)} \in(0,1)$, we get the unique solution

$$
\begin{gathered}
q_{(1)}^{*}=\frac{c-\alpha_{1} \delta}{c-\alpha_{1} \delta+w-\epsilon}=\frac{B-\sqrt{B^{2}-4 c \delta \epsilon}}{2 \delta \epsilon} \\
\Rightarrow U_{1}=\alpha_{1}=\frac{B-\sqrt{B^{2}-4 c \delta \epsilon}}{2 \delta}
\end{gathered}
$$

where $B=c-\epsilon+\delta \epsilon+w>0$. The continuation value $\alpha_{1}$ measures the remainer's desire to stay in the costly conflict. A positive $\alpha_{1}$ shows that the player is willing to fight continuously even without support from the alliance.

The early quitter P2 stops paying the fighting cost right after her concession. Meanwhile she may get the second winning prize $\epsilon$ in each period with probability 
$q_{(1)}$ which is the alliance's winning probability. The timing of receiving the prize can be any $t$ from the period of her surrender to infinity. Therefore, her expected utility is

$$
\begin{aligned}
U_{2} & =(0+\epsilon) q_{(1)}+\left[1-q_{(1)}\right]\left[1-p_{(1)}\right] \delta(0+\epsilon) q_{(1)}+\cdots \\
& =\frac{\epsilon q_{(1)}}{1-\left[1-q_{(1)}\right]\left[1-p_{(1)}\right] \delta} \\
& =: \alpha_{2}>0
\end{aligned}
$$

The expected utility to surrender measures a consumer's incentive to free ride. A positive $\alpha_{2}$ shows that each consumer on the demand side wishes to free ride on the benefit of her/his ally's contribution. Moreover, we find that the following inequality always holds given that the firm plays a mixed strategy.

$$
\begin{gathered}
\alpha_{2}>\alpha_{1}>0, \quad \forall q_{(1)} \in(0,1) \\
\Rightarrow \overbrace{\left.U_{i}(S)\right|_{a_{-i}=F}>\underbrace{U_{i}^{\left.U_{i}(F)\right|_{a_{-i}=S}}>\left.U_{i}(S)\right|_{a_{-i}=S}=0}_{\text {incentive to fight (morality) }},}^{\text {incentive to free ride (selfishness) }}, \quad i=1,2
\end{gathered}
$$

The intuition of the last inequality is as follows. In the case where a win to the demand side does not require every one's contribution, each consumer hopes to be the only early quitter and gets the highest utility $\left.U_{i}(S)\right|_{a_{-i}=F}$, that is, when consumer $i$ surrenders and the remaining ally fights alone. If a consumer failed to be the first quitter, she/he would stay in the conflict rather than follow the quitter and obtains the lower utility $\left.U_{i}(F)\right|_{a_{-i}=S}$. However, the incentive to free ride may lead to an unpleasant result. If both players quit at the same time, they get zero utility. There is de facto 'no ride'. Both players may be better off by staying in the conflict longer.

The expected time of obtaining a winning prize $E D_{(1)}$ is the expected length of the State-1 game.

$$
\begin{aligned}
E D_{(1)}= & \lim _{t \rightarrow+\infty} 1\left\{1-\left[1-q_{(1)}\right]\left[1-p_{(1)}\right]\right\} \\
& +2\left[1-q_{(1)}\right]\left[1-p_{(1)}\right]\left\{1-\left[1-q_{(1)}\right]\left[1-p_{(1)}\right]\right\}+\cdots \\
= & \sum_{t=1}^{+\infty} t\left\{\left[1-q_{(1)}\right]\left[1-p_{(1)}\right]\right\}^{t-1}\left\{1-\left[1-q_{(1)}\right]\left[1-p_{(1)}\right]\right\} \\
= & \frac{1}{p_{(1)}\left[1-q_{(1)}\right]+q_{(1)}}
\end{aligned}
$$

Now, we move to State-2 in which two consumers actively fight against the firm. Consumers' strategies are assumed to be stationary as long as the state of the game does not change, i.e., before any player concedes. We assume that identical 
consumers play symmetric strategies. Analogous to the above, we solve the indifference conditions. To the firm P3,

$$
\begin{array}{r}
U_{3}(F)=U_{3}(S) \\
\Rightarrow\left[-2 m+\beta_{3} \delta\right]\left[1-p_{(2)}\right]^{2}+\left[-m+\beta_{1} \delta\right]\left[1-p_{(2)}\right] p_{(2)} \\
+\left[-m+\beta_{2} \delta\right] p_{(2)}\left[1-p_{(2)}\right]+v\left[p_{(2)}\right]^{2}=0
\end{array}
$$

where the continuation values $\beta \mathrm{s}=0$ at equilibrium. Since the quitting probability $p_{(2)} \in(0,1)$, we get a unique solution to individual consumer's quitting probability

$$
p_{(2)}^{*}=\frac{-m+\sqrt{m^{2}+2 m v}}{v}
$$

To active consumers P $i$ where $i=1,2$,

$$
\begin{array}{r}
U_{i}(F)=U_{i}(S) \\
\Rightarrow\left[-c+\alpha_{3} \delta\right]\left[1-p_{(2)}\right]\left[1-q_{(2)}\right]+\left[-c+\alpha_{1} \delta\right] p_{(2)}\left[1-q_{(2)}\right]+w q_{(2)} \\
=\left[0+\alpha_{2} \delta\right]\left[1-p_{(2)}\right]\left[1-q_{(2)}\right]+\epsilon q_{(2)}
\end{array}
$$

where at equilibrium, the continuation value is

$$
\begin{aligned}
\alpha_{3} & =\left[1-p_{(2)}\right] U_{i}(F)+p_{(2)} U_{i}(S) \\
& =\alpha_{2} \delta\left[1-p_{(2)}\right]\left[1-q_{(2)}\right]+\epsilon q_{(2)} .
\end{aligned}
$$

We get

$$
q_{(2)}^{*}=\frac{c-\delta\left[-\alpha_{2}+\alpha_{3}+\left(\alpha_{1}+\alpha_{2}-\alpha_{3}\right) p_{(2)}^{*}\right]}{c-\delta\left[-\alpha_{2}+\alpha_{3}+\left(\alpha_{1}+\alpha_{2}-\alpha_{3}\right) p_{(2)}^{*}\right]+w-\epsilon} .
$$

Plug $\alpha$ s and $p_{(2)}^{*}$, we find a unique solution to $q_{(2)}^{*}$. The solution is reported in the appendix.

Proposition 1 There is a unique mixed strategy Nash equilibrium $\left(p_{(2)}^{*}, p_{(2)}^{*}, q_{(2)}^{*}\right)$ in a two-against-one game where two identical players on the demand side are assumed to play symmetric strategies.

The following results are derived when we compare the equilibrium strategies in two states.

$\operatorname{Lemma}$
$\quad \frac{\partial p_{(2)}}{\partial w}=\frac{\partial p_{(1)}}{\partial w}=0$

Lemma $3.2 \frac{\partial p_{(2)}}{\partial \delta}=\frac{\partial p_{(1)}}{\partial \delta}=0$ 
Lemma $3.3 p_{(2)}^{*}>p_{(1)}^{*}$ and

$$
q_{(2)}^{*}<q_{(1)}^{*} \quad \text { if } \quad \alpha_{3}>\alpha_{1}+\alpha_{2}
$$

The first Lemma shows that, to the remaining consumer, the free rider's winning prize would not affect his own strategy at equilibrium. It is in line with our setting: players are selfish but not altruistic. Together with the second equation, we know that the incentive to free ride (selfishness) dominates regardless how low the potential free riding benefit is, which is measured by the second winning prize $\epsilon$, or how strong the desire to fight (morality) is, which is measured by the first winning prize $w$. The second Lemma coincides with the standard war of attrition. The discount factor does not change active allies' strategies at equilibrium. However, it matters to the firm's strategies as Eqs. (3) and (7) show. The third Lemma shows that, comparing the equilibrium strategies in two states, the players on two sides act differently. Consumers, driven by the selfish motivations, are more likely to leave the conflict when potential support from the alliance exists. Soon we will see that their quitting probabilities increase in the size of the demand side $n$. Meanwhile, the firm surrenders with slightly lower probability when facing two players' challenge if and only if the continuation values satisfy the condition $\alpha_{3}>\alpha_{1}+\alpha_{2}$. We can provide numerical solutions to the firm's quitting probabilities which shows that $q_{(n)}$ may fluctuate with the number of consumers $n$ around $q_{(1)}^{*}$ depending on the values we give. Nevertheless it has a clear slow increasing trend. The numerical solutions are available upon request.

\section{A generalized case: $n$-against-one game}

Now we consider a game where the firm is a large polluting firm that serves many consumers in the market. The game of war of attrition between $n$ consumers and one firm is as illustrated in Table 3. Note that we change some notations as the following. The actions $S\left(F_{k}\right)$ represent the case where player $i$ surrenders and $k$ consumers fight. The actions $F\left(F_{k-1}\right)$ represent the joint actions of $k$ active fighting consumers where player $i$ is among them. In either case, the game will continue in State- $k$ in the next period. We denote the winning prize to the firm to be $v_{(n)}$ indexed by the number of consumers $n$. It is, as before, assumed to be large enough to cover one period of fighting cost. Thus, it ensures the existence of mixed strategy equilibria-the firm would not quit the conflict in the first period. The prize is tempting enough for the firm to stay in the costly war of attrition. It is natural to assume that the winning prize to the firm increases in $n$. In a large economy, a big firm that serves many consumers would generate more sales revenue. For simplicity, let $v_{(n)}=v n$.

As before, we assume that $n$ players on the demand side play symmetric strategy. The quitting probability $p_{(n)}$ is the solution to the firm's indifference condition

$$
\begin{aligned}
& U_{o}(F)=U_{o}(S) \\
\Leftrightarrow & \sum_{k=1}^{n}[-k m] C_{n}^{k}\left[1-p_{(n)}\right]^{k}\left[p_{(n)}\right]^{n-k}+v_{(n)}\left[p_{(n)}\right]^{n}=0 \\
\Leftrightarrow & m n p_{(n)}+v_{(n)}\left[p_{(n)}\right]^{n}=m n
\end{aligned}
$$


Table 3 A game of war of attrition between $n$ consumers and one firm

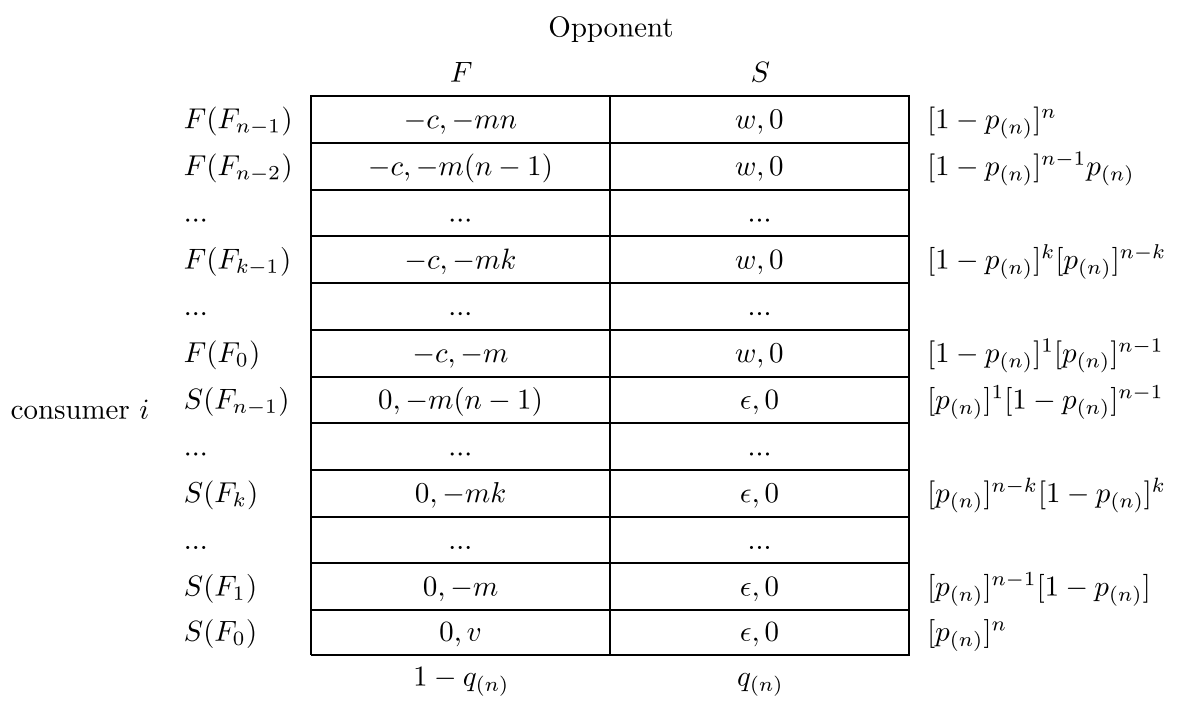

The actions of the other players on the demand side in parentheses. $F_{k-1}$ represents the case where among the other $n-1$ consumers on the demand side, there are $k-1$ fighters and $n-k$ quitters. The flow payoff to player $i$ and the firm are in the cells. The payoffs to other allies, either active fighters or early quitters, are not shown in the table. The stopping probabilities are $\left(p_{(n)}, \ldots, p_{(n)}, q_{(n)}\right)$ where $n$ represents the number of the remaining players on the demand side. Identical consumers are assumed to play the same strategy if the state of the game does not change. The mixed strategy equilibrium is $\left(p_{(n)}^{*}, \ldots, p_{(n)}^{*}, q_{(n)}^{*}\right)$ in State- $n$. In State- $n$ at equilibrium, the continuation values to player $i$ are $\alpha_{a_{i}, k}$ where $a_{i}$ is player $i$ 's action, either fight $F$ or surrender $S$. $k$ is the number of active fighters excluding player $i$. There are $2 n-1$ continuation values for player $i$. At equilibrium, the continuation values to the firm are always zero therefore not highlighted separately

$$
\Leftrightarrow \quad m p_{(n)}+v\left[p_{(n)}\right]^{n}=m
$$

where $C_{n}^{k}=\left(\begin{array}{l}n \\ k\end{array}\right)$ is a binomial coefficient. $k$ represents the number of active fighters. The continuation values $\beta \mathrm{s}=0$ at equilibrium therefore omitted. For any $n>0$, $m>0$ and $v_{(n)}>m n$, Eq. (9) has a positive root in the range of $(0,1)$, a negative root and $n-2$ imaginary roots if $n$ is an even number. If instead $n$ is odd, the equation has a positive root in the range of $(0,1)$ and $n-1$ imaginary roots. The following results are derived.

Lemma 4.1 Consumers' quitting probabilities $p_{(n)}$ increase in the size of the alliance $n$. consumers fight less hard when having potential support from the alliance.

Proof of Lemma 4.1 Rewriting the indifference condition Eq. (9), we define the function $X\left(p_{(n)}\right)=m p_{(n)}+v\left[p_{(n)}\right]^{n}-m$. By the implicit function theorem

$$
\partial p_{(n)} / \partial n=-\frac{\partial X(\cdot) / \partial n}{\partial X(\cdot) / \partial p_{(n)}}=-\frac{\left[p_{(n)}\right]^{n} v \ln p_{(n)}}{m+n\left[p_{(n)}\right]^{n-1} v}>0
$$


Lemma 4.2 In an n-against-one game where the firm fights against a side of $n$ consumers, when the number of consumers goes to infinity, there is a unique solution to consumer's quitting probability $\lim _{n \rightarrow+\infty} p_{(n)}^{*}$ at equilibrium at the limit. The limit of $p_{(n)}^{*}$ is 1 .

Proof of Lemma 4.2 First we prove that there exists a unique real solution $p_{(n)}$ s.t. $X\left(p_{(n)}\right)=0$ for any given $m, n, v>0$. It is clear that $X\left(p_{(n)}\right)$ is continuous on the interval $[0,1] . X(0) \rightarrow-m<0$ when $p_{(n)} \rightarrow 0$ and $X(1) \rightarrow v>0$ when $p_{(n)} \rightarrow 1$. By the Intermediate Value Theorem, there exists at least one $p \in(0,1)$ s.t. $X(p)=0$. Suppose there are two solutions $p_{1}$ and $p_{2}$ s.t. $p_{1} \neq p_{2}$ and $X\left(p_{1}\right)=X\left(p_{2}\right)=0$. By Rolle's theorem, it implies that $X^{\prime}(p)=0$. But $X^{\prime}(p)=m+n\left[p_{(n)}\right]^{n-1} v>0$ which is a contradiction.

Now we find the limit. We view $p_{(n)}$ as a sequence with $0<p_{(n)}<1$ satisfying Eq. (9):

$$
m p_{(n)}+v\left[p_{(n)}\right]^{n}=m
$$

Divide by $p_{(n)}$ and let $y=v / m$,

$$
\text { LHS : }=1+y\left[p_{(n)}\right]^{n-1}=\frac{1}{p_{(n)}}=: R H S
$$

Suppose that the limit of $p_{(n)}$ is not 1 . Since $p_{(n)}$ increases in $n$, the limit, if there exists any, must be close to 1 . Denote the limit as $\widetilde{p} \pm \gamma$ where $\gamma$ is some small number. We thus have $(\tilde{p} \pm \gamma)^{n-1} \rightarrow 0$ as $n \rightarrow \infty$. Plugging this into the LHS gives us $1+y[\tilde{p} \pm \gamma]^{n-1} \rightarrow 1$ while the RHS goes above 1 , which is a contradiction. Therefore, the limit of an individual consumer's quitting probability is

$$
\lim _{n \rightarrow+\infty} p_{(n)}=1 .
$$

Plug it in Eq. (9), we immediately get the following results:

$$
\begin{gathered}
{\left[p_{(n)}\right]^{n} \rightarrow 0} \\
{\left[1-p_{(n)}\right]^{n} \rightarrow 0}
\end{gathered}
$$

The limits tell us how consumers' behave in boycott. In the very first period, an individual consumer will surrender immediately almost surely driven by free riding incentives. However, not all of them will surrender. That is to say, the polluting firm, will only face limited boycotting power from the consumers, however, the boycott will not end soon, given the infinitely large amount of consumers. Some will act as 'loyal supporters of the product' who would not boycott the firm while the rest will act as 'strict environmentalists' who boycott for a considerable long period of time. The firm thus would expect to suffer some financial loss and damage to corporate image from the boycott. However, being patient enough, such loss will reduce over time due to the decreasing number of active boycotters. 
To the firm, the quitting probability $q_{(n)}$ is the solution to an individual consumer's indifference condition

$$
\begin{aligned}
& U_{i}(F)=U_{i}(S), \quad i \in\{1,2, \ldots, n\} \\
& \Rightarrow w q_{(n)}+\left[1-q_{(n)}\right] \sum_{k=0}^{n-1}\left(-c+\alpha_{F, k} \delta\right)\left[1-p_{(n)}\right]^{k} C_{n-1}^{k}\left[p_{(n)}\right]^{n-1-k} \\
& \quad=\epsilon q_{(n)}+\left[1-q_{(n)}\right] \sum_{k=1}^{n-1} \alpha_{S, k} \delta\left[1-p_{(n)}\right]^{k} C_{n-1}^{k}\left[p_{(n)}\right]^{n-1-k}
\end{aligned}
$$

where $k$ represents the number of fighters excluding player $i$. The continuation values $\alpha_{F, k}$ and $\alpha_{S, k}$ (indexed by $k$ ) are strictly positive and upper bounded at equilibrium. There are overall $2 n-1$ continuation values in State- $n$. When there are $k$ active fighters remain in the conflict,

$$
\begin{aligned}
\alpha_{F, k-1} & =\alpha_{F, k-1}\left(p_{(k)}, q_{(k)}\right) \\
& =\epsilon q_{(k)}+\sum_{i=1}^{k-1} \alpha_{S, i} \delta\left[\left[1-p_{(k)}\right]^{i} C_{k-1}^{i}\left[p_{(k)}\right]^{k-1-i}\left[1-q_{(k)}\right]\right]
\end{aligned}
$$

represents the continuation value that player $i$ fights with $k-1$ remainers and

$$
\begin{aligned}
\alpha_{S, k}= & \alpha_{S, k}\left(p_{(k)}, q_{(k)}\right) \\
= & \frac{1}{1-\left[1-p_{(k)}\right]^{k}\left[1-q_{(k)}\right] \delta} \\
& \quad \times\left\{\epsilon q_{(k)}+\sum_{i=1}^{k-1} \alpha_{S, i} \delta\left[\left[1-p_{(k)}\right]^{i} C_{k}^{i}\left[p_{(k)}\right]^{k-i}\left[1-q_{(k)}\right]\right]\right\}
\end{aligned}
$$

represents the continuation value that player $i$ surrenders and $k$ players remain in the conflict. In particular, when every player on the demand side surrenders, the game ends immediately and therefore there is no continuation value.

$$
\alpha_{S, 0}:=0
$$

The following results are derived.

Lemma 4.3 In an n-against-one game where the firm fights against a side of $n$ consumers, when the number of consumers goes to infinity, there is a unique solution to 
the firm's quitting probability $\lim _{n \rightarrow+\infty} q_{(n)}^{*}$ at equilibrium at the limit..$^{5}$ The limit of $q_{(n)}^{*}$ is a function of $c, w, \epsilon$ and less than 1. That is, the firm tends not to surrender and always plays mixed strategies.

Proof of Lemma 4.3 We rewrite the indifference condition (13), for $q_{(n)} \in(0,1), \delta \in(0,1)$,

$$
\begin{aligned}
w q_{(n)}+\left[1-q_{(n)}\right] c+\left[1-q_{(n)}\right]\left\{\sum_{k=0}^{n-1} \alpha_{F, k} \delta\left[1-p_{(n)}\right]^{k} C_{n-1}^{k}\left[p_{(n)}\right]^{n-1-k}\right\} \\
=\epsilon q_{(n)}+\left[1-q_{(n)}\right] \sum_{k=0}^{n-1} \alpha_{S, k} \delta\left[1-p_{(n)}\right]^{k} C_{n-1}^{k}\left[p_{(n)}\right]^{n-1-k} \\
\Rightarrow \alpha_{F, n-1}\left[1-p_{(n)}\right]^{n-1}+\sum_{k=0}^{n-2} \alpha_{F, k}\left[1-p_{(n)}\right]^{k} C_{n-1}^{k}\left[p_{(n)}\right]^{n-1-k} \\
\quad-\sum_{k=1}^{n-1} \alpha_{S, k}\left[1-p_{(n)}\right]^{k} C_{n-1}^{k}\left[p_{(n)}\right]^{n-1-k} \\
=\frac{1}{\left[1-q_{(n)}\right] \delta}\left\{c\left[1-q_{(n)}\right]-w q_{(n)}+\epsilon q_{(n)}\right\}
\end{aligned}
$$

where the continuation values $\alpha_{F, k}$ and $\alpha_{s, k}, \forall k$ are upper bounded and certainly, for example, less than $w$ which is the maximum utility an individual consumer can possibly get. The continuation value $\alpha_{F, n-1}=\alpha_{F, n-1}\left(p_{(n)}, q_{(n)}\right)$ is a function of $p_{(n)}$ and $q_{(n)}$. Therefore we write it separately. We take the limit on both sides.

$$
\begin{aligned}
\lim _{n \rightarrow+\infty} L H S= & \lim _{n \rightarrow+\infty}\left\{\alpha_{F, n-1}\left[1-p_{(n)}\right]^{n-1}+\sum_{k=0}^{n-2} \alpha_{F, k}\left[1-p_{(n)}\right]^{k} C_{n-1}^{k}\left[p_{(n)}\right]^{n-1-k}\right. \\
& \left.\quad-\sum_{k=1}^{n-1} \alpha_{S, k}\left[1-p_{(n)}\right]^{k} C_{n-1}^{k}\left[p_{(n)}\right]^{n-1-k}\right\} \\
= & \lim _{n \rightarrow+\infty} \alpha_{F, n-1}\left[1-p_{(n)}\right]^{n-1} \\
& +\lim _{n \rightarrow+\infty} \sum_{k=0}^{n-2} \alpha_{F, k}\left[1-p_{(n)}\right]^{k} C_{n-1}^{k}\left[p_{(n)}\right]^{n-1-k} \\
& -\lim _{n \rightarrow+\infty} \sum_{k=1}^{n-1} \alpha_{S, k}\left[1-p_{(n)}\right]^{k} C_{n-1}^{k}\left[p_{(n)}\right]^{n-1-k}
\end{aligned}
$$

\footnotetext{
${ }^{5}$ The numerical solution for $q_{(n)}$ where $n=1,2, \ldots, 5$ given different $\epsilon \mathrm{S}$ is available upon request. It shows that $q_{(n)}$ fluctuate and increase slowly with $n$. It implies that the size of the firm has limited impacts on firm's strategy making.
} 
The first term of Eq. (18) goes to zero at the limit since $\alpha_{F, n-1}$ is upper bounded and $\left[1-p_{(n)}\right]^{n-1} \rightarrow 0$. Now we show that second term, and by the same argument, the last term also approaches zero. Let $G_{(k)}=\left[1-p_{(n)}\right]^{k} C_{n-1}^{k}\left[p_{(n)}\right]^{n-1-k}$. The greatest value $\bar{G}$, or called the mode, is given by $k=(n-1-1) p_{(n)}=n p_{(n)}$ if $k$ is an integer; otherwise, the greatest value is given by largest integer $k$ such that $k \leq n p_{(n)}$.

$$
\bar{G}=\left(1-p_{(n)}\right)^{n p_{(n)}} p_{(n)}^{-1+n-n p_{(n)}} C_{n-1}^{n p_{(n)}}
$$

To find the limit of $q_{(n)}$, now we try to find an upper bound for $p_{(n)}$ which is lower than one. We consider this: $\forall j$ such that $n>j>0$,

$$
p_{(n)} \leq \widetilde{p}:=1-\frac{j}{n} \text { for large } n
$$

This must hold. ${ }^{67}$ Then we have

$$
p_{(n)}^{n} \leq \tilde{p}:=\left(1-\frac{j}{n}\right)^{n} \rightarrow e^{-j}>0
$$

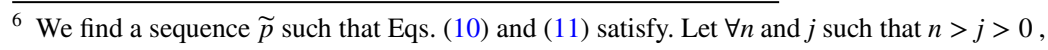

$$
\tilde{p}:=1-\frac{j}{n}
$$

$\forall k>0, \widetilde{p}=1-\frac{j}{n}$ is monotonically increasing in $n$.

$$
\lim _{n \rightarrow \infty} \widetilde{p}=1-\frac{j}{n}=1
$$

and

$$
\widetilde{p}^{n}=\left(1-\frac{j}{n}\right)^{n}=\left[\left(1-\frac{1}{\frac{n}{j}}\right)^{\frac{n}{j}}\right]^{j}=\left(e^{-1}\right)^{j}=e^{-j} \in(0,1)
$$

As $n \rightarrow+\infty$,

$$
\left[1-\left(1-\frac{j}{n}\right)\right]^{k} C_{n-1}^{k}\left[1-\frac{j}{n}\right]^{n-1-k} \rightarrow \frac{e^{-j} j^{k}}{\Gamma(1+k)} \in(0,1)
$$

and

$$
\sum_{k=0}^{\infty} \frac{e^{-j} j^{k}}{\Gamma(1+k)}=1
$$

${ }^{7}$ The upper bound $\tilde{p}$ is good enough to find the limit of $q_{(n)}$. We can proof, for example, that for $b<1, p_{(n)} \leq \widetilde{p}_{1}:=1-b \frac{\ln n}{n}$ is a even lower upper bound. We can also show that for a small finite $n$, $p_{(n)} \leq \widetilde{p}_{2}:=1-\frac{b}{1+b n}$. The proofs are available upon request. 
Plugging $\widetilde{p}$ into Eq. (19), we find that for any countable $n>0$ and $p_{(n)}$ that satisfies Eqs. (10)-(12), when $n$ increases to infinity,

$$
\bar{G}=\frac{(1-j / n)^{j}(j / n)^{-j+n} n C_{n-1}^{n-j}}{n-j} \rightarrow 0
$$

And,

$$
\begin{aligned}
\sum_{k=0}^{n-2} \alpha_{F, k}\left[1-p_{(n)}\right]^{k} C_{n-1}^{k}\left[p_{(n)}\right]^{n-1-k} & <\sum_{k=0}^{n-2} w\left(1-p_{(n)}\right)^{n p_{(n)}} p_{(n)}^{-1+n-n p_{(n)}} C_{n-1}^{n p_{(n)}} \\
& =(n-1) w\left(1-p_{(n)}\right)^{n p_{(n)}} p_{(n)}^{-1+n-n p_{(n)}} C_{n-1}^{n p_{(n)}} \\
& <(n-1) w \frac{(1-j / n)^{j}(j / n)^{-j+n} n C_{n-1}^{n-j}}{n-j} \rightarrow 0
\end{aligned}
$$

Analogously, the last term of Eq. (17) approaches zero at the limit, which makes the left hand side a summation of three zeros.

The limit of the right hand side of Eq. (17) is

$$
\begin{aligned}
& \lim _{n \rightarrow+\infty} R H S=\lim _{n \rightarrow+\infty} L H S \\
& \quad \Leftrightarrow \lim _{n \rightarrow+\infty} \frac{1}{\left[1-q_{(n)}\right] \delta}\left\{c\left[1-q_{(n)}\right]-w q_{(n)}+\epsilon q_{(n)}\right\}=0 \\
& \quad \Leftrightarrow \lim _{n \rightarrow+\infty} \frac{1}{\left[1-q_{(n)}\right] \delta}=0
\end{aligned}
$$

$$
\text { or } \lim _{n \rightarrow+\infty} c\left[1-q_{(n)}\right]-w q_{(n)}+\epsilon q_{(n)}=0
$$

Equality (21) is true if and only if $\lim _{n \rightarrow+\infty}\left[1-q_{(n)}\right] \delta \rightarrow+\infty$, that is, $\lim _{n \rightarrow+\infty} q_{(n)} \rightarrow-\infty$ which cannot be true. Therefore, Equality (22) gives the unique solution for the limit of $q_{(n)}$.

$$
\lim _{n \rightarrow+\infty} q_{(n)}=\frac{c}{c+w-\epsilon}
$$

Proposition 2 In an n-against-one game where the firm fights against a side of $n$ consumers, when the number of consumers goes to infinity, there exists a unique 
equilibrium $\left(p_{(n)}^{*}, \ldots, p_{(n)}^{*}, q_{(n)}^{*}\right)$ in the game where identical players on the demand side are assumed to play symmetric strategies.

\section{Conclusion}

We develop an uneven game of war of attrition between a weak alliance of two consumers and one firm. We examine the extension of free riding incentives and alliance advantage to Maynard Smith (1974) classic war of attrition under complete information. While two sides play a war of attrition, two consumers on one side play a prisoner's dilemma against each other. We allow the free rider to get a prize if the game eventually ends with his ally's success. We derive the Nash equilibrium and compare the results to that of a classic one-against-one war of attrition. To the alliance, we find that selfish motivation overcomes moral concern-free riding incentives dominate regardless how strong the willingness to beat the firm is. Consumers fight less hard when having more potential support from the alliance. The consumer's probability to surrender increases to one much quicker when compared to the firm's equilibrium strategy.

We then extend the model to a general case where the size of the demand side increases. When the market size goes to infinitely large, we find that both sides quit the game with higher probabilities at equilibrium. Consumers would surrender immediately almost surely. Meanwhile, the firm's equilibrium strategies do not change significantly regardless of the number of the competitors. Therefore, the game slowly becomes a one sided war of attrition where the firm cannot be defeated easily by the consumers.

We employ the model to explain consumer boycott where consumers on the demand side fight against a misbehaved monopolist on the supply side. Our results suggest that in a market where a big firm serves many consumers, the real boycotting power is limited by consumers' free riding incentives. Over time the polluting firm suffers less costs due to the decreasing number of active boycotters. That is to say, for a strong enough firm that can survive the first several tough periods, the game will slowly favor the amoral firm and make it difficult for the consumers to win. Another possible real life application of this model can be labor strike where mass employees fight against the employer that offers unfair wages. The results therefore suggest the importance of third party intervention, either by the government or a non-profit organization. To make a boycott or a strike more effective and successful, a well-organized boycott is recommended.

Acknowledgements Open access funding provided by University of Helsinki including Helsinki University Central Hospital. The author would like to thank the Editor and two anonymous reviewers. I certify that there is no actual or potential conflict of interest in relation to this article. The author follows the ethical obligations in accordance with the policy of the Eurasian Economic Review. 
Open Access This article is distributed under the terms of the Creative Commons Attribution 4.0 International License (http://creativecommons.org/licenses/by/4.0/), which permits unrestricted use, distribution, and reproduction in any medium, provided you give appropriate credit to the original author(s) and the source, provide a link to the Creative Commons license, and indicate if changes were made.

\section{Appendix}

The detailed solution to the firm's quitting probabilities at equilibrium at State- 2 in Eq. (7) is

$$
\begin{aligned}
q_{(2)}^{*}= & \left(4 \alpha_{2} \delta^{2} m^{2}+\delta\left(-\alpha_{1}+\alpha_{2}(-1+8 \delta)-\epsilon\right) m v-4 \alpha_{2} \delta^{2} m \sqrt{m(m+2 v)}\right. \\
& +\alpha_{1} \delta v \sqrt{m(m+2 v)}+\alpha_{2} \delta v \sqrt{m(m+2 v)}-4 \alpha_{2} \delta^{2} v \sqrt{m(m+2 v)} \\
& +\delta \epsilon v \sqrt{m(m+2 v)}-v^{2}\left(c-\epsilon+\delta\left(\alpha_{2}-2 \alpha_{2} \delta+\epsilon\right)+w\right) \\
& +v^{2}\left[1 / v^{4}(-4 \delta(m+v-\sqrt{m(m+2 v)})\right. \\
& \times\left(\epsilon v-\alpha_{2} \delta(m+v-\sqrt{m(m+2 v)})\right)\left(c v^{2}+\alpha_{1} \delta v(m-\sqrt{m(m+2 v)})\right. \\
& \left.+\alpha_{2} \delta(m+v-\sqrt{m(m+2 v)})(v-\delta(m+v)+\delta \sqrt{m(m+2 v)})\right) \\
& +\left(c v^{2}+(-1+\delta) \epsilon v^{2}+\delta\left(\alpha_{1}+\epsilon\right) v(m-\sqrt{m(m+2 v)})\right. \\
& +\alpha_{2} \delta(m+v-\sqrt{m(m+2 v)})(v-2 \delta(m+v) \\
& \left.\left.\left.\left.+2 \delta \sqrt{m(m+2 v)})+v^{2} w\right)^{2}\right)\right)\right] /(2 \delta(-m-v \\
& \left.+\sqrt{m(m+2 v)})\left(\epsilon v-\alpha_{2} \delta(m+v)+\alpha_{2} \delta \sqrt{m(m+2 v)}\right)\right)
\end{aligned}
$$

where $\alpha_{1}$ and $\alpha_{2}$ are as Eqs. (2) and (4) show. The solution is calculated by Mathematica.

\section{References}

Baron, D. P. (2001). Private politics, corporate social responsibility, and integrated strategy. Journal of Economics and Management Strategy, 10(1), 7-45.

Bulow, J., \& Klemperer, P. (1999). The generalized war of attrition. American Economic Review, 89(1), 175-189.

Craig Smith, N. (1990). Morality and the market: Consumer pressure for corporate accountability. London: Routledge.

da Silva Rocha, A. B. (2017). Cooperation in the well-mixed two-population snowdrift game with punishment enforced through different mechanisms. Advances in Complex Systems, 20(04n05), 1750010.

da Silva Rocha, A. B., Escobedo, R., \& Laruelle, A. (2015). Emergence of cooperation in phenotypically heterogeneous populations: A replicator dynamics analysis. Journal of Statistical Mechanics Theory and Experiment, 2015(6), P06003. 
da Silva Rocha, A. B., \& Salomão, G. M. (2019). Environmental policy regulation and corporate compliance inevolutionary game models with well-mixed and structured populations. European Journal of Operational Research.

Delacote, P. (2008). 13 contributions of game theory to the analysis of consumer boycotts. Game Theory and Policymaking in Natural Resources and the Environment, 9, 266.

Egorov, G., \& Harstad, B. (2017). Private politics and public regulation. The Review of Economic Studies, 84(4), 1652-1682.

Fehr, E., \& Fischbacher, U. (2004). Third-party punishment and social norms. Evolution and Human Behavior, 25(2), 63-87.

Friedman, M. (1991). Consumer boycotts: A conceptual framework and research agenda. Journal of Social Issues, 47(1), 149-168.

Haigh, J., \& Cannings, C. (1989). The n-person war of attrition. Acta Applicandae Mathematica, 14(1-2), 59-74.

Heijnen, P., \& van der Made, A. (2012). A signaling theory of consumer boycotts. Journal of Environmental Economics and Management, 63(3), 404-418.

Helgesson, P., \& Wennberg, B. (2015). The n-player war of attrition in the limit of infinitely many players. Dynamic Games and Applications, 5(1), 65-93.

Innes, R. (2006). A theory of consumer boycotts under symmetric information and imperfect competition. The Economic Journal, 116(511), 355-381.

John, A., \& Klein, J. (2003). The boycott puzzle: Consumer motivations for purchase sacrifice. Management Science, 49(9), 1196-1209.

Laruelle, A., da Silva Rocha, A. B., \& Escobedo, R. (2018). The hawk-dove game in phenotypically homogeneous and heterogeneous populations of finite dimension. Communications in Nonlinear Science and Numerical Simulation, 55, 56-67.

Maynard Smith, J. (1974). The theory of games and the evolution of animal conflicts. Journal of Theoretical Biology, 47(1), 209-221.

Maynard Smith, J., \& Price, G. R. (1973). The logic of animal conflict. Nature, 246(5427), 15.

Peck, J. (2017). Temporary boycotts as self-fulfilling disruptions of markets. Journal of Economic Theory, $169,1-12$.

Powell, R. (2017). Taking sides in wars of attrition. American Political Science Review, 111(2), 219-236.

Tyran, J. R., \& Engelmann, D. (2005). To buy or not to buy? An experimental study of consumer boycotts in retail markets. Economica, 72(285), 1-16.

Publisher's Note Springer Nature remains neutral with regard to jurisdictional claims in published maps and institutional affiliations. 